\title{
LA PLANIFICACIÓN LINGÜÍSTICA EN LA UNIVERSIDAD DE COSTA RICA: POLÍTICA LINGÜÍSTICA DE LENGUAJE INCLUSIVO DE GÉNERO, SU EJECUCIÓN Y RELACIÓN CON PROPUESTAS DE UNIVERSIDADES HISPANOHABLANTES
}

Silvia Rivera Alfaro

\section{(c) ${ }_{\mathrm{EY}} \mathrm{NC} \mathrm{ND}_{\mathrm{ND}}$}

Doi: https://doi.org/10.15517/rfl.v45i2.39162

URL: https://revistas.ucr.ac.cr/index.php/filyling/index 



\title{
LA PLANIFICACIÓN LINGÜÍSTICA EN LA UNIVERSIDAD DE COSTA RICA: POLÍTICA LINGÜÍSTICA DE LENGUAJE INCLUSIVO DE GÉNERO, SU EJECUCIÓN Y RELACIÓN CON PROPUESTAS DE UNIVERSIDADES HISPANOHABLANTES LINGUISTIC PLANNING AT THE UNIVERSITY OF COSTA RICA: GENDER FAIR USE OF LANGUAGE POLICY, ITS EXECUTION AND RELATIONSHIP TO PROPOSALS OF SPANISH SPEAKING UNIVERSITIES
}

Silvia Rivera Alfaro

\begin{abstract}
RESUMEN
En este artículo analizamos la política y planificación lingüística (PPL) de uso de lenguaje inclusivo de género de la Universidad de Costa Rica (UCR), de su creación al presente, relacionándola con propuestas que surgen en otras instituciones de educación superior del mundo hispanohablante. Con una perspectiva glotopolítica, describimos la PPL (Cooper, 1997) y su instrumento (CIEM, 2004); exploramos la ejecución de la PPL en documentos administrativos y noticias de la Rectoría; y contextualizamos la PPL de la UCR tras analizar las guías de uso no sexista del lenguaje de otras universidades hispanohablantes. Entre los principales resultados, tenemos que esta política y su instrumento, así como la manera en que buscan implementarse, no han sido claras, con consecuencias glotopolíticas como el posible rechazo de la comunidad universitaria; la implementación de la política es mayor en documentos administrativos; también, en los documentos de la Rectoría existen estrategias lingüísticas que coinciden con propuestas de otras guías y no aparecen en CIEM (2004), lo cual puede ser un insumo para la UCR. Discutimos sobre la necesidad de encontrar mecanismos de implementación relacionados con concientizar a la comunidad sobre la relación de la política lingüística con la realidad institucional y el sexismo en la academia en general (Canal UCR, 2017). Palabras clave: Política lingüística; planificación lingüística; glotopolítica; lenguaje inclusivo de género; lenguaje no sexista.
\end{abstract}

\section{ABSTRACT}

In this paper we analyse the gender fair use of language policy and planning (LPP) of the University of Costa Rica (UCR), since it was created in 2003 to the present, relating it to proposals by other Spanish speaking institutions of higher education. With a glottopolitical perspective, we describe this LPP(Cooper, 1997) and its instrument (CIEM, 2004); we explore the execution of the LPP in administrative documents and news of the Dean Office; and we contextualize the LPP of UCR by analyzing the guidelines of non sexist use of language created by other Spanish speaker universities. Among the results, we have: this policy and its instrument neither the way they should be implemented have not been clear, with possible glottopolitical consequences, such as the rejection of the university community; the implementation of this policy is higher among the administrative documents; in addition, at the Dean documents we find linguistic strategies that coincide with some of the guidelines from other universities and do not appear at CIEM (2004), this can result as an input for UCR. We disscuse about the urge of finding mechanisms of implementation related to raise awareness among the community about the relationship of the LPP with the institutional reality and sexism in the academic world in general (Canal UCR, 2017).

Keywords: Language policy; language planning; glottopolitics; gender fair use of language; non sexist language.

M. L. Silvia Rivera Alfaro. Investigadora del Centro de Investigación y Estudios de la Mujer (CIEM). Universidad de Costa Rica. Costa Rica. Estudiante, Ph.D. Program in Latin American, Iberian, and Latino Cultures (LAILAC). The Graduate Center, City University of New York. Estados Unidos.

Correo electrónico: silvia.riveralfaro@gmail.com

Recepción: 16- 01- 19

Aceptación: 07- 03- 19 


\section{Introducción}

La Universidad de Costa Rica (UCR) se define como una institución de conocimiento con propósitos sociales y políticos con respecto a la realidad contemporánea (Ocampo Álvarez, 2010); busca contribuir a la transformación de la realidad social por distintos medios. De acuerdo con su estatuto (Consejo Universitario [CU], 1974), la UCR está en la obligación de crear políticas que puedan funcionar como un ejemplo para la sociedad costarricense. En este marco, entre otras políticas, la UCR definió en 2003 un acuerdo sobre el uso de lenguaje inclusivo de género (CU, 2003); este acuerdo, que puede entenderse como una política lingüística ${ }^{1}$, en 2007 se convirtió en política universitaria (CU, 2006).

Sin embargo, después de la creación de esta política lingüística, prácticamente no se llevaron a cabo acciones para acompañar su desarrollo; por lo tanto, el círculo de la discusión pública, planificación lingüística, ejecución y evaluación de la política (Gazzola, 2017) no puede ser seguido. En este contexto, una primera aproximación a la planificación de lenguaje inclusivo de género de la UCR requirió tomar decisiones para definir qué aspectos de la política, la comunidad y los textos producidos en dicho marco podrían estudiarse.

Este artículo revisa algunos de los principales resultados del proyecto La planificación lingüística de la Universidad de Costa Rica: de la política lingüística de uso de lenguaje inclusivo de género a su ejecución textual (Rivera Alfaro, 2018). Aunque entendemos que no es posible generalizar a partir de un caso específico, los aspectos de una política y planificación lingüística (PPL en adelante) de lenguaje inclusivo de género a nivel universitario, con un foco en sus posibles consecuencias en una comunidad académica (UCR) específica, podría permitirnos un punto de partida para posteriores trabajos. Así las cosas, el objetivo principal de este artículo es analizar la política universitaria de uso de lenguaje inclusivo de género de la Universidad de Costa Rica, desde su creación (en 2003) hasta el presente, relacionándola con propuestas de uso de lenguaje inclusivo surgidas en el ámbito universitario hispanohablante; se trata de un primer acercamiento a esta política universitaria que procura comprenderla no como un fenómeno aislado, sino asociada a la realidad local e internacional.

\section{Metodología}

Estudiar una política lingüística requiere, en primer lugar, de un posicionamiento frente al concepto de lenguaje ${ }^{2}$. El nuestro nos permite comprender la relación de la lengua

1 Una política lingüística es una medida definida por un actor, generalmente de poder, con respecto al uso de una(s) lengua(s) en determinados contextos y depende de aspectos sociopolíticos, tales como reivindicaciones sociales de grupos, fortalecimiento de identidades (Cooper, 1997) o decisiones políticoadministrativas (Gazzola, 2017). Por su parte, la planificación lingüística (campo que será nombrado en lo sucesivo como PPL por política y planificación lingüística) "comprende los esfuerzos deliberados por influir en el comportamiento de otras personas respecto de la adquisición, la estructura o la asignación funcional de sus códigos lingüísticos" (Cooper, 1997, p. 60); son las actividades que se realizan para operativizar una política lingüística y no se restringen a lo estatal, sino que, desde una perspectiva ecológica, entienden la lengua como un elemento de interacción social que incluye múltiples factores sociolingüísticos (Infoterm, 2005). La PPL es política, finalmente: presenta una dimensión persuasiva que se manifiesta en un nivel ideológico-discursivo (del Valle, 2007), sobrepasa la dimensión de la lengua y tiene más relación con los objetivos (Cooper, 1997), el contexto y, por tanto, lo político.

2 Fairclough (2001) critica que la ciencia del lenguaje construyó la lengua como un objeto abstracto 
con la sociedad y, especialmente, con la política: entendemos el lenguaje como un fenómeno sígnico e ideológico ${ }^{3}$ que surge en el territorio interindividual (con individuos socialmente organizados, que forman parte de colectivos) (Voloshinov, 2009). En otras palabras, el lenguaje por sí mismo, como objeto, implica las relaciones entre individualidades y colectividades y es un instrumento social ligado de manera fundamental al contexto ${ }^{4}$, al cual pertenecen dichos individuos y colectivos. Podemos ampliar nuestra definición añadiendo que desde la PPL se ha considerado el lenguaje como "un ámbito de la vida social susceptible de ser objeto de la acción política” (del Valle, 2014, p. 90); y desde el ámbito glotopolítico, donde se considera una concepción más contextual, se aborda más la articulación amplia de lenguaje y política como la participación del lenguaje tanto en organizar asuntos de Estado como en negociar "cualquier situación en la que haya una distribución desigual del poder" (Joseph, citado por del Valle, 2014, p. 91 $)^{5}$. Según esta visión, el lenguaje se sitúa en la acción colectiva, lo cual implica que se relaciona con aspectos como poder, autoridad y legitimidad (del Valle, 2007); para dicha perspectiva el poder no está en el lenguaje, sino que es el lenguaje el que está inserto en la arena política: el poder se representa, se manifiesta, se simboliza por medio del lenguaje (entre otros medios), pero el poder reside realmente en el contexto, en las condiciones institucionales de producción y recepción de las palabras, donde están inscritas las personas (Bourdieu, 2008).

A partir de las consideraciones que hemos desarrollado, podemos pasar a nuestras propias definiciones para lenguaje inclusivo y lenguaje inclusivo de género. (Es importante mantener presente la complejidad del contexto, como entramado donde la estructura social crea complejas tensiones y dominaciones, en el cual se insertan estos usos del lenguaje). Así, el lenguaje inclusivo es el nombre que se utiliza para designar ciertos usos (estrategias) del lenguaje que llevan a cabo las personas usuarias de la lengua con el fin de hacer explícito su posicionamiento ideológico de no discriminar por distintas razones -como discapacidad, género y raza- ${ }^{6}$. En otras palabras, el lenguaje inclusivo es un posicionamiento político y una orientación de quien(es) escribe(n)/habla(n) hacia el contexto: implica cómo lo concibe(n) y

aislado de la historia y la realidad social; y Bourdieu (2008) evidencia que dicho objeto abstracto se incorpora en la teoría lingüística generalmente como un objeto preconstruido y, de este modo, se olvida no solo la realidad social, sino la génesis social y las leyes sociales de construcción del lenguaje, además de los aspectos políticos que implica.

3 Para Voloshinov (2009) todo signo presenta una materialidad (sonido, tela, color) y se produce en la relación entre individuos que están políticamente organizados, de manera que los signos cumplen una función dentro de dicha organización y se comprenden a partir de otros signos, por lo cual son ideológicos. Para el autor, "todo producto ideológico posee una significación: representa, reproduce, sustituye algo que se encuentra fuera de él, esto es, aparece como signo" (Voloshinov, 2009, p. 26); por ello, señala que se puede poner un símbolo de igualdad entre el signo y la ideología.

4 En del Valle (2007), puede leerse sobre la importancia de tomar en cuenta el contexto dentro del concepto de lenguaje para la comprensión de la relación lengua-política en trabajos como el que aquí nos compete.

5 Esta perspectiva resulta de mayor utilidad para nuestro trabajo, dado que no restringe las funciones de la lengua o el accionar con ella al ámbito estatal (como lo hizo en su momento inicial la PPL y que hemos evidenciado con Cooper, 1997) y nos permite mantener clara la PPL, en un sentido más amplio, en el que una organización también puede crear su propia política en cuanto a un aspecto de la lengua (Infoterm, 2005; Auroux, 2009).

6 Tenemos presente que este posicionamiento puede ser asumido también por distintas motivaciones (todas ideológicas). Por ejemplo, puede ser usado para ganar popularidad en la política, sin un interés real en la inclusión. 
cómo quiere(n) posicionarse ante este (del Valle, 2014). Del concepto anterior, se desprende que el lenguaje inclusivo de género es un posicionamiento ideológico que implica la utilización de ciertas estrategias lingüísticas para evidenciar que quien escribe/habla busca la equidad entre hombres y mujeres y que, por tanto, busca su representación equitativa a nivel textual y discursivo ${ }^{7}$.

Para aproximarnos a un tema complejo, tal como es una política de uso de lenguaje inclusivo de género que no había sido estudiada previamente, utilizamos una variedad de métodos. Primero, examinamos la historia y definición de la PPL de la UCR por medio de una revisión bibliográfica que incluye archivos de distintas instancias universitarias; luego, analizamos la guía publicada por el Centro de Investigación y Estudios de la Mujer (CIEM, 2004) como respuesta a la decisión universitaria, y observamos los cambios de la política a lo largo del tiempo.

Dado que se trata de un proyecto de carácter exploratorio, buscamos sobrepasar el nivel de descripción de la política (Cooper, 1997) y tratamos de describir también su ejecución de acuerdo con las posibilidades de la investigadora. Para este propósito, a partir de un criterio cualitativo, seleccionamos un único agente de la universidad para ser estudiado: la rectoría, la cual es descrita por el estatuto institucional como la instancia encargada de que se ejecuten las políticas (CU, 1974) y, por tanto, podría ser entendida como una instancia 'cuyas prácticas son ejemplares' en cuanto a las políticas universitarias. En este nivel, en el proyecto seleccionamos dos tipos de textos publicados en línea por la rectoría durante 2015 en su página web: las noticias y los documentos administrativos; la elección se justifica en el hecho de que son textos producidos para destinatarios colectivos de la comunidad universitaria y, en este modo, promueven ciertas representaciones con respecto a las personas que forman parte de dicha comunidad.

El corpus está compuesto por 22 documentos administrativos y 99 noticias. Entre los documentos administrativos encontramos 5 circulares, 4 resoluciones y 13 acuerdos; en total estos documentos suman 127 páginas para un total aproximado de 34786 palabras. Por su parte, en 2015 la rectoría publicó 108 textos en la sección de noticias; de ellos descartamos 9 por no tratarse de noticias propiamente, sino afiches o cronogramas. De este modo, la muestra quedó compuesta por 99 noticias cuya longitud variaba de 120 a 710 palabras y, en total, sumaban un aproximado de 54719 palabras.

$7 \quad$ La promoción de este uso fue iniciada por las feministas estadounidenses en los años sesenta; a esta etapa Cooper (1997) la caracteriza como una campaña. Sin embargo, en la actualidad ha sido adoptado como política lingüística en distintas instancias a nivel internacional, regional, local e institucional; por ejemplo, es una política de la UNESCO, el Consejo de Europa, España, universidades e instituciones de España y América Latina. Por ello, considerando el lenguaje inclusivo de género como planificación lingüística, Pauwels (1998) identifica algunos posicionamientos sobre la propuesta de lenguaje inclusivo de género. El primero es el de disrupción lingüística. Esta posición se caracteriza por proponer cambios morfológicos en las palabras y tomar en cuenta las diferentes partes del discurso. El segundo es creación de un lenguaje que pueda centrarse en la experiencia de la mujer para incluir su realidad. Actualmente, algunos sectores también entienden el lenguaje inclusivo de género como una reforma lingüística que busca la visibilización de las mujeres en el lenguaje (Vázquez Hermosilla y Santaemilia Ruiz, 2011). Por ejemplo, Dorner (2010) trata sobre las bases, los métodos y las disciplinas implicadas en la reforma. Nos parece necesario traer a colación esta última definición, pues evidencia la relación del lenguaje y lo político que señala nuestra definición de lenguaje inclusivo de género. Las propuestas para lograr dicha reforma varían según la lengua en la cual busquen implementarse y según el momento en que se realizan. Un ejemplo de esto es que en el ámbito universitario hispanohablante existen soluciones de distintos niveles (léxico-gramatical y discursivo). 
Con el fin de analizar los textos, utilizamos herramientas procedentes del análisis del discurso; particularmente tomamos la categoría de indicidad (Hanks, 2000), porque resultaba operativa para relacionar los diversos participantes de la universidad, de quienes hacían mención los textos, con el contexto institucional y la ejecución de la política. Al respecto, pusimos atención a cada mención de participantes de la comunidad, clasificamos dichos participantes (por ejemplo: autoridades, estudiantes, personal administrativo) y el modo en el cual eran indizados (usando estrategias de lenguaje inclusivo de género o no). Consideramos el uso de las estrategias de lenguaje inclusivo de género como un índice de ejecución de la política; con este propósito, distinguimos entre las estrategias propuestas en la guía de la universidad (CIEM, 2004) y aquellas que podrían ser categorizadas como "otras estrategias" de lenguaje inclusivo de género, pero que no formaban parte del instrumento de la UCR.

Posteriormente, dado que uno de los retos de hacer frente a este complejo objeto de estudio era no aislar la política de la UCR de otras políticas similares del universo del cual forma parte la institución, en el proyecto también se analizaron las guías de uso de lenguaje inclusivo de género que habían sido publicadas en línea (hasta enero de 2016) por otras universidades de habla hispana. Luego de esto, relacionamos las estrategias de la universidad (de la guía y la ejecución de la política) con las estrategias propuestas por el resto de las universidades.

A lo largo del trabajo, mantuvimos una perspectiva glotopolítica ${ }^{8}$ y observamos las posibles consecuencias glotopolíticas (del Valle, 2007 y 2013; Narvaja de Arnoux y del Valle, 2010) de la política, su ejecución, y las estrategias propuestas. Posteriormente, discutimos los resultados a la luz de otros estudios relacionados con nuestros distintos pasos de investigación y con el contexto institucional.

\section{La política lingüística de uso de lenguaje inclusivo de género de la UCR}

\subsection{La política lingüística y su instrumento}

La política lingüística de la Universidad de Costa Rica sobre uso de lenguaje inclusivo de género fue primero establecida como un acuerdo del Consejo Universitario (CU, 2003), entre otros propósitos, para cumplir el principio y objetivos de la institución en su relación con la sociedad (CU, 1974). El CU definió esta medida en un contexto con las condiciones propicias para hacerlo: los estudios de género en la UCR tenían casi dos décadas de desarrollo (Guzmán Stein, 1997); la institución tenía tanto investigación como activismo en el tema (CIEM, 2001; Guzmán Stein, 2001 y 2002; Guzmán Stein y Letendre Morales, 2003); las mujeres habían ganado espacios en la política institucional (por ejemplo, en 2004 la UCR tuvo su primera decana); además, nacional e internacionalmente el tema de los derechos de la mujer

$8 \quad$ La glotopolítica o política del lenguaje es una disciplina que se ubica cerca de la sociología del lenguaje y se enfoca en los aspectos políticos del lenguaje, sin olvidar lo social ni lo cultural; de manera sucinta, podría definirse como la acción política sobre el lenguaje (Narvaja de Arnoux y del Valle, 2010). Parafraseando a Guespin y Marcellesi (1986), glotopolítica hace referencia a los diversos aspectos, conscientes o inconscientes, de la acción política sobre el lenguaje: incluye hechos relacionados con el lenguaje (uso de una lengua en sí, aspectos discursivos, etc.) y acciones sociales que revierten la forma de lo político; por ejemplo, el mantenimiento de un tipo de texto para un fín determinado o el uso de una lengua para ciertos fines y no otras (legitimación del estatus de una lengua); llama la atención sobre el hecho de que toda política lingüística, al aplicarse, trae consigo implicaciones y consecuencias glotopolíticas (Guespin y Marcellesi, 1986). 
era discutido, lo cual resulta un hecho crucial para definir la política lingüística, pues el CU cita en su acuerdo al menos a una institución internacional (UNESCO) que había tomado cartas en el asunto (del lenguaje inclusivo).

Como se puede observar, el CU tomó la decisión por medio de la formulación de un problema/objetivo; en otras palabras, relacionó la decisión con una discusión social mucho más grande que había sido previamente identificada como un problema por otras organizaciones. A pesar de que había reportes con respecto a la situación de las mujeres en la Universidad, el Consejo no incluyó esta información en la discusión para crear la política. En otras palabras, en la enunciación de la política hay una falta de claridad con respecto a su vínculo con el contexto universitario inmediato y con otras políticas de género de la universidad. Este es un hecho que podemos rastrear también cuando el acuerdo se convierte en política en 2007 (CU, 2006) y a lo largo de los años (CU, 2007, 2008a, 2008b, y 2014). No es sino hasta la política universitaria de 2016-2020 cuando observamos que se enuncia la relación de la política lingüística con las políticas de género en general (CU, 2015).

Desde el momento en que fue establecida como un acuerdo, esta política lingüística únicamente toma en consideración el nivel de uso; además, no incluye ninguna definición de lenguaje inclusivo de género. Adicionalmente, encontramos que la comunidad universitaria tuvo pocos incentivos para adoptar la política más allá de su carácter obligatorio: hubo pocos talleres y actividades para crear consciencia de la relación de la PPL con la comunidad y su situación (Liz Robles Hernández, comunicación personal, 14 de enero de 2016; Martínez Rocha, 2009; Huertas Jiménez, 2003). En este sentido, debemos agregar que, conforme pasó el tiempo, hubo también un rechazo hacia las propuestas de uso de lenguaje inclusivo de género por parte de algunos actores políticos tanto a nivel internacional (Lemus, 2001; Bosque, 2012) como a nivel institucional (O'neal Coto, 2012).

Dada la falta de claridad en la formulación de la PPL, analizamos el instrumento publicado por el CIEM (2004) en respuesta a la formulación del acuerdo (Carcedo, 2007): el documento podría actuar como un complemento a la enunciación de la política lingüística. No obstante, hay algunas características que vienen a nuestra consideración tras observar con más detalle dicho material.

Primero que todo, debemos señalar que el documento es una reimpresión de una adaptación institucional de una guía creada por otra organización, el Centro de Investigación para la Acción Femenina (CIPAF) de República Dominicana. Así, el documento carece de una relación con la PPL. En términos de nuestro estudio, en el instrumento encontramos algunos mecanismos de oficialización, es decir, la explicitación de situaciones en las cuales la política debe seguirse; empero, no encontramos suficiente institucionalización, es decir, elementos que demuestren la relación formal del documento con su contexto institucional. Tampoco aparecen suficientes elementos de legitimación, es decir, marcos políticos o legales regionales, nacionales o internacionales con los cuales se relaciona la PPL. En esta línea, en la guía tampoco encontramos enunciados sus objetivos con claridad.

La segunda característica por comentar de la guía es su falta de conceptos. No explicita conceptos de lenguaje, tampoco la relación de la lengua y el contexto (sociedad, política, otro) ni una definición de lenguaje inclusivo de género. Únicamente tenemos referencia al objetivo de utilizar el lenguaje inclusivo de género en un sentido amplio: no reforzar estereotipos de género.

La tercera característica está relacionada con las propuestas de la guía. Mayoritariamente se enfocan en el nivel morfosintáctico, pero el instrumento también incluye enunciados acerca de lo que se puede decir y cómo debe ser dicho con respecto a ciertos temas. En la guía, 
incluso encontramos referencia a decisiones administrativas que se escapan de la cuestión de uso del lenguaje.

Estas características podrían llevar al rechazo de la política lingüística por su asociación a la idea de lo políticamente correcto (Courtine, 2006). Además, sin una apropiación crítica de la política y por la carencia de incentivos para reflexionar sobre el lenguaje, la política lingüística podría ser entendida, por una parte de la comunidad, como causante de efectos negativos. Por ejemplo, podría ser entendida como una manera de prohibición que afecta la libertad de cátedra de la comunidad; o podría ser entendida como un medio de separación en que, si no se siguen las reglas del lenguaje inclusivo de género como el código correcto, las personas pueden ser separadas del grupo; o incluso puede haber intimidación $n^{9}$, si una persona siente que podría ser castigada por no seguir la política lingüística (Bordieu, 2008; Foucault, 2002).

\subsection{Una primera aproximación a la ejecución de la política}

Con el fin de llevar a cabo una primera aproximación a la ejecución de la política lingüística, analizamos las noticias y los documentos administrativos publicados por la rectoría en su sitio web durante $2015^{10}$. El corpus consiste de 22 documentos administrativos (aproximadamente 34784 palabras) y 99 noticias (aproximadamente 54719 palabras). Tomamos en consideración las diferentes características de cada género (Charaudeau, 2004; Charaudeau y Maingueneau, 2005); este es un elemento clave para un primer conocimiento de cómo operan las estrategias y la ejecución de la política.

Primero, si consideramos el uso de lenguaje inclusivo de género sumando la cantidad de estrategias propuestas en la guía universitaria (IP) del CIEM (2004) con las otras posibles estrategias de uso de lenguaje inclusivo de género (OIP), encontramos que solo existe una pequeña diferencia entre la ejecución de la política entre los documentos administrativos (88.9\%) y las noticias (79 \%). La Figura 1 demuestra esta diferencia.

No obstante, si prestamos atención solo a las estrategias presentes en la guía universitaria, encontramos que IP es mucho mayor para los documentos administrativos $(71.2 \%$ vs. $36 \%)$; por otro lado, otras posibles estrategias devienen más frecuentes en las noticias (38.3\%) que en los documentos administrativos (17.7\%).

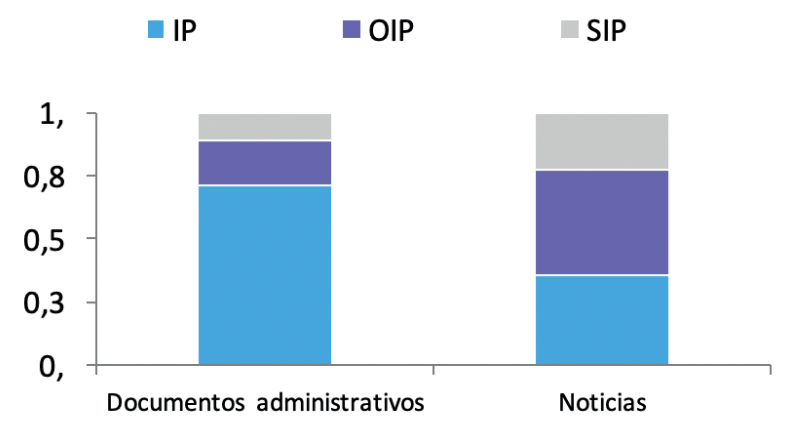

Figura 1. Porcentaje de estrategias de lenguaje inclusivo de género utilizadas por género textual

$9 \quad$ No obstante, esta es una consecuencia que depende del sentimiento e interpretación de una persona y no del modo en que sea enunciada la PPL.

10 Por razones de espacio, en este artículo nos enfocaremos solo en resultados comparativos. En Rivera Alfaro (2018) se encuentra una descripción detallada de cada uno de los géneros de manera separada. 
Esto nos hace preguntarnos si las propuestas de la guía de la UCR (CIEM, 2004) son más efectivas para los documentos administrativos que para las noticias. Al mismo tiempo, nos lleva a considerar que las estrategias de la guía podrían resultar insuficientes, al menos para las noticias, pero podrían ser insuficientes también para otros géneros que nuestro estudio no consideró.

Aunque discutiremos las estrategias de lenguaje inclusivo de género con más detalle en §3.3, podemos observar las más utilizadas para IP y OIP. De este modo, tenemos dos estrategias IP más comunes. Una de ellas es el uso de colectivización / desespecificación (una categoría emergente durante el proceso de investigación que será discutida más adelante), tal como en 'rectoría' o 'dirección', con $24.9 \%$ en los documentos administrativos y $47.9 \%$ en las noticias. La otra es el uso de sustantivos colectivos, tales como 'comunidad', con $46.9 \%$ en los documentos administrativos frente a $39.4 \%$ en las noticias.

En cuanto a las estrategias OIP, las más comunes son distintas en cada género. Para los documentos administrativos es el uso del paréntesis, con $44.4 \%$, como en 'decano(a)'. En cambio, la frecuencia más alta para las noticias es la explicitación de la persona específica y su género, con $79.9 \%$. Estos resultados podrían ser vistos en relación con los géneros: mientras el paréntesis aparece con más frecuencia en la sección de destinatarios de las cartas u otros documentos, en formas como director(a), las noticias usualmente señalan las personas participantes de los eventos que narran, como ‘el rector Jenning Hensen' o ‘la diputada Patricia Mora'.

Finalmente, otra característica de las noticias como género textual que llegó a ser importante durante el análisis fue el uso de la imagen y otros modos (O’Halloran, 2012). Conforme analizamos las noticias, observamos la necesidad emergente de tomar en cuenta al menos el uso de imágenes; de esta manera, nos enfocamos en la primera imagen del texto, que aparece en conjunto con el título y la bajada o pie de foto, y su relación con las estrategias verbales de lenguaje inclusivo de género. Con este paso nos dimos cuenta de que, incluso cuando existe un alto porcentaje de frecuencia de estrategias de lenguaje inclusivo de género en el texto (con lo cual podría ser tomado como inclusivo), las imágenes representan de manera diferenciada a hombres y mujeres.

Analizar las fotografías nos permitió entender que la estrategia OIP de especificar la persona y su género en el texto podría funcionar como una cortina de humo: pareciera que, si tenemos más mujeres en el papel principal en la fotografía, no son nombradas. La fotografía de una noticia (Mora Vargas, 13 de mayo de 2015) representa un panel mixto durante el Foro Institucional 2015 con la participación de 3 mujeres y 1 hombre, cuyas identidades no son referidas en el pie de foto, que solo hace referencia a los campos de conocimiento que representan; si continuamos leyendo el cuerpo de la noticia, encontramos nombres de hombres que no aparecen en la fotografía, pero no logramos encontrar quiénes son las mujeres ni tampoco su relación con la institución. Esto puede llevar a menores posibilidades para las mujeres de ser recordadas como parte de los grupos políticos de la universidad.

Por su parte, las fotografías de hombres en papeles principales no solo incluyen sus nombres, sino que también evalúan positivamente su trayectoria. En la fotografía de otra noticia (Mora Vargas, 14 de octubre de 2015) podemos ver un panel de la misma actividad, pero esta vez solo conformado por hombres. En este caso, encontramos sus nombres en el pie de foto; además, si leemos el resto del texto, podemos encontrar elementos valorativos, tal como experto.

Después de analizar los textos, podemos relacionar nuestros resultados con posibles efectos glotopolíticos que fueron mencionados anteriormente. Por ejemplo, en el Acuerdo del Consejo Universitario R-162-2015, encontramos la idea de corrección en el corpus: 


\section{CAPÍTULO II \\ MIEMBROS DEL CONSEJO UNIVERSITARIO}

ARTÍCULO 4. Conformación del Consejo Univeritario

De conformidad con el Estatuto Orgánico, el Consejo Universitario está conformado de la siguiente forma:

a) Una persona del sector académico por cada área y una por las Sedes Regionales.

b) Una persona del sector administrativo.

c) Dos personas representantes estudiantiles.

d) Una persona representante de la Federación de Colegios Profesionales Universitarios.

e) La persona que ocupa la Rectoría

f) El ministro o la ministra de Educación Pública en calidad de miembro honorario, con voz y voto, quien no contará para efectos de cuórum. (Rectoría, 2015b, p. 4)

En la sección c, “dos personas representantes estudiantiles” puede entenderse como una forma de hipercorrección, dado que "dos representantes estudiantiles" es ya una forma de lenguaje inclusivo de género en castellano, pues no implica una marca de género.

El otro punto por desarrollarse es el de la estrategia de colectivización/desespecificación, el cual es una estrategia muy frecuente en los textos, tal como hemos mencionado. Como estrategia, este procedimiento consiste en moverse semánticamente del eje de referente sexuado (ej. rector / rectora) hacia el eje de concreción-abstracción (rector / rectora - rectoría). Este movimiento hacia la abstracción podría causar un cambio en la manera en que comprendemos a las personas participantes de una acción: en una frase con un referente sexuado es más fácil determinar participantes del evento; por el contrario, cuando hay participantes indizados por medio del movimiento al eje de abstracción la entidad se hace borrosa, se diluye en una organización, lo cual podría causar ambigüedad.

En español, en una frase como "la dirección organizó el evento", no es claro si el evento fue organizado por la persona que encabeza la oficina o si todas las personas que trabajan en ella colaboraron. A pesar de que prestar atención a este fenómeno se encontraba fuera de los límites de nuestro trabajo, es posible considerar que, al estudiarlo en detalle, encontraríamos razones políticas por las cuales quien escribe / habla prefiere una de las formas para crear un efecto específico. Por ejemplo, la ambigüedad podría resultar de utilidad para disminuir la responsabilidad de una persona en una determinada situación; dicho de otro modo, hay una diferencia cualitativa entre: "la rectoría admitió su falta" y "el rector / la rectora admitió su falta".

\subsection{El instrumento de la UCR y las estrategias de lenguaje inclusivo de género en relación con las propuestas de otras universidades}

Tal como enfatizamos, la relación de la ejecución de la política lingüística de la UCR con las propuestas de otras instituciones de educación superior es importante para entender el lugar de esta política como parte de un fenómeno más grande. Además de la guía de la UCR, hasta enero del 2016 encontramos otras 17 guías universitarias de uso de lenguaje inclusivo de género en español; 16 de esos instrumentos fueron creados en España y solo uno fue publicado en América Latina, específicamente por otra institución costarricense, la Universidad Nacional. Nuestro objetivo ${ }^{11}$ en esta sección es resumir la comparación de dichas guías y la de la UCR.

11 Para los propósitos de este trabajo no prestaremos atención a las características de las guías, tales como sus objetivos, conceptos y otras categorías que utilizamos también en el instrumento de la UCR; un análisis detallado puede encontrarse en Rivera Alfaro (2018). 
En términos de características generales, estas guías varían de 4 a 162 páginas, para un promedio de 42-43 páginas; la guía de la UCR se acerca al promedio, con una extensión de 33 páginas. Con respecto a la autoría, solo 7 de los 17 instrumentos explicitan autoría (y 2 de estos instrumentos pertenecen a una misma autora); estos 7 documentos fueron escritos por profesionales del área del lenguaje. El instrumento de la UCR incluye el nombre de la persona que adaptó el material para la institución; sin embargo, en contraste con esas 7 guías, no fue escrita por una persona especialista en lenguaje.

Con respecto a los conceptos, el instrumento creado por la UCR coincide con los otros 6 que no explicitan el concepto de lenguaje; además, coincide con la mayoría (14) que no incluye una definición de lenguaje inclusivo de género, a pesar de que 11 guías presentan elementos que podrían estar relacionados con una definición y algunas introducen un concepto de sexismo en el lenguaje o lenguaje androcéntrico, tal como lo hace la guía de la UCR.

En cuanto a las operaciones relacionadas con el contexto (oficialización, institucionalización, legitimación), los mecanismos de oficialización se encontraron solo en 3 de las 17 guías; la UCR es parte de este grupo que presenta elementos de esta categoría. Con respecto a la institucionalización, encontramos que solo 9 guías presentan este mecanismo: la guía de la UCR es parte de los documentos que carecen de él. Por otra parte, en cuanto a los procedimientos de legitimación, observamos que son bastante comunes en las 17 guías, en comparación con el instrumento creado por la UCR, donde son prácticamente inexistentes.

Ahora nos enfocamos en las estrategias propuestas para el uso de lenguaje inclusivo de género. La Tabla 1 resume y compara las estrategias encontradas en la ejecución de la política en los textos emitidos por la rectoría en 2015, la guía de la UCR y los instrumentos de otras universidades. Algunas de estas estrategias serán comentadas posteriormente.

Tabla 1. Comparación de estrategias: guías de universidades hispanohablantes, guía de la UCR y ejecución de la PPL en textos emitidos por la rectoría en 2015

\begin{tabular}{|c|c|c|c|c|}
\hline Categoría & Propuesta & $\begin{array}{c}\text { Guías } \\
\text { universitarias }\end{array}$ & Guía UCR & $\begin{array}{c}\text { Ejecución } \\
\text { política UCR }\end{array}$ \\
\hline \multirow{4}{*}{$\begin{array}{l}\text { Uso de } \\
\text { determinados tipos } \\
\text { de sustantivos }\end{array}$} & Uso de genéricos & $\checkmark$ & $\checkmark$ & $\checkmark$ \\
\hline & Uso de epicenos & $\checkmark$ & $\checkmark$ & $\checkmark$ \\
\hline & Uso de abstractos & $\checkmark$ & $\begin{array}{l}\text { *colectivización/ } \\
\text { desespecificación }\end{array}$ & $\checkmark$ \\
\hline & Uso de colectivos & $\checkmark$ & $\checkmark$ & $\checkmark$ \\
\hline
\end{tabular}




\begin{tabular}{|c|c|c|c|c|}
\hline \multirow{7}{*}{$\begin{array}{l}\text { Uso de femenino y } \\
\text { masculino }\end{array}$} & $\begin{array}{l}\text { Uso de formas } \\
\text { dobles para destacar } \\
\text { ambos géneros } \\
\text { (reduplicación) }\end{array}$ & $\checkmark$ & $\checkmark$ & $\checkmark$ \\
\hline & $\begin{array}{l}\text { Alternancia } \\
\text { del femenino y } \\
\text { masculino }\end{array}$ & $\checkmark$ & No & NA* \\
\hline & $\begin{array}{l}\text { Coordinación de } \\
\text { adjetivo en las } \\
\text { formas dobles con el } \\
\text { último elemento de } \\
\text { la forma } \\
\text { *Solo aparece en } \\
\text { Escrig Gil y Sales } \\
\text { Boix (2010) }\end{array}$ & $\checkmark$ & No & No \\
\hline & $\begin{array}{l}\text { Preferencia: en } \\
\text { formas dobles } \\
\text { agregar a las mujeres } \\
\text { primero cuando se } \\
\text { habla de ámbitos } \\
\text { masculinizados } \\
\text { *Solo aparece en } \\
\text { Escrig Gil y Sales } \\
\text { Boix (2010), no se } \\
\text { propone lo inverso. }\end{array}$ & $\checkmark$ & No & No \\
\hline & $\begin{array}{l}\text { Uso de forma } \\
\text { concreta para la } \\
\text { persona a la que } \\
\text { se está refiriendo } \\
\text { cuando se trata de } \\
\text { una sola persona }\end{array}$ & $\checkmark$ & No & $\checkmark$ \\
\hline & $\begin{array}{l}\text { Simetría en fórmulas } \\
\text { de tratamiento }\end{array}$ & $\checkmark$ & No & No \\
\hline & $\begin{array}{l}\text { Aposiciones, } \\
\text { explicación tras } \\
\text { la utilización del } \\
\text { masculino }\end{array}$ & $\checkmark$ & $\checkmark$ & No \\
\hline \multirow{2}{*}{ Uso de perífrasis } & $\begin{array}{l}\text { Sustitución } \\
\text { de sustantivos } \\
\text { masculinos } \\
\end{array}$ & $\checkmark$ & \multirow{2}{*}{$\checkmark$} & \multirow{2}{*}{ *perífrasis } \\
\hline & $\begin{array}{l}\text { Inclusión de } \\
\text { algunas expresiones } \\
\text { específicas }\end{array}$ & $\checkmark$ & & \\
\hline
\end{tabular}




\begin{tabular}{|c|c|c|c|c|}
\hline \multirow{6}{*}{$\begin{array}{l}\text { Sustitución } \\
\text { de artículos, } \\
\text { pronombres o } \\
\text { adjetivos con } \\
\text { marca de género } \\
\text { gramatical // } \\
\text { Uso de pronombres }\end{array}$} & $\begin{array}{l}\text { Sustitución de } \\
\text { artículos definidos }\end{array}$ & $\checkmark$ & $\checkmark$ & $\checkmark$ \\
\hline & $\begin{array}{l}\text { Sustitución de } \\
\text { pronombres relativos } \\
\text { con determinante } e l \\
\text { que / la que }\end{array}$ & $\checkmark$ & No & $\checkmark$ \\
\hline & $\begin{array}{l}\text { Sustitución de la } \\
\text { expresión del mismo } \\
\text { o de los mismos }\end{array}$ & $\checkmark$ & No & NA* \\
\hline & $\begin{array}{l}\text { Sustitución de } \\
\text { indefinidos uno, } \\
\text { todo, alguno y sus } \\
\text { plurales }\end{array}$ & $\checkmark$ & No & $\mathrm{NA}^{*}$ \\
\hline & $\begin{array}{l}\text { Sustitución de objeto } \\
\text { directo masculino } \\
\text { por objeto indirecto }\end{array}$ & No & $\checkmark$ & $\checkmark$ \\
\hline & $\begin{array}{l}\text { Uso del pronombre } \\
\text { de segunda persona } \\
\text { singular "usted" }\end{array}$ & No & No & $\checkmark$ \\
\hline \multirow{6}{*}{$\begin{array}{l}\text { Omisión de } \\
\text { términos } \\
\text { masculinos (como } \\
\text { determinantes y } \\
\text { referencias directas } \\
\text { al sujeto) }\end{array}$} & $\begin{array}{l}\text { Uso de formas } \\
\text { determinantes sin } \\
\text { marca de género }\end{array}$ & $\checkmark$ & No & $\checkmark$ \\
\hline & $\begin{array}{l}\text { Eliminación de la } \\
\text { palabra 'nosotros' } \\
\text { del plural de } \\
\text { modestia y mantener } \\
\text { solo los verbos }\end{array}$ & $\checkmark$ & No & $\mathrm{NA}^{*}$ \\
\hline & $\begin{array}{l}\text { Cambio de frases. } \\
\text { Uso de expresiones } \\
\text { sinonímicas }\end{array}$ & $\checkmark$ & *perífrasis & $\checkmark$ \\
\hline & $\begin{array}{l}\text { Eliminación } \\
\text { de artículo en } \\
\text { sustantivos comunes } \\
\text { en cuanto al género }\end{array}$ & $\checkmark$ & No & $\checkmark$ \\
\hline & $\begin{array}{l}\text { Estructuras con "se" } \\
\text { (se pronominal, } \\
\text { impersonal, pasivo) }\end{array}$ & $\checkmark$ & No & $\mathrm{NA}^{*}$ \\
\hline & $\begin{array}{l}\text { Transformar las } \\
\text { oraciones pasivas en } \\
\text { activas }\end{array}$ & $\checkmark$ & No & $\mathrm{NA}^{*}$ \\
\hline \multirow{2}{*}{ Uso de otros signos } & Uso de barras / & $\checkmark$ & No & Sí \\
\hline & Usode @ & $\checkmark$ & No & No \\
\hline
\end{tabular}




\begin{tabular}{|c|c|c|c|c|}
\hline $\begin{array}{l}\text { Uso de referencias } \\
\text { específicas }\end{array}$ & $\begin{array}{l}\text { Utilizar } \\
\text { denominaciones } \\
\text { recomendadas } \\
\text { para enseñanza } \\
\text { universitaria y } \\
\text { títulos }\end{array}$ & $\checkmark$ & No & $\mathrm{NA}^{*}$ \\
\hline \multirow{7}{*}{$\begin{array}{l}\text { El mantenimiento } \\
\text { de los referentes } \\
\text { por procedimientos } \\
\text { léxicos } \\
\text { *Solo en Rojas } \\
\text { Blanco y Rojas } \\
\text { Porras (2015) }\end{array}$} & $\begin{array}{l}\text { Repeticiones exactas } \\
\text { o parciales }\end{array}$ & $\checkmark$ & No & \multirow{7}{*}{$* \checkmark$} \\
\hline & $\begin{array}{l}\text { Repeticiones con } \\
\text { transformaciones } \\
\text { gramaticales }\end{array}$ & $\checkmark$ & No & \\
\hline & $\begin{array}{l}\text { Sustitución por } \\
\text { sinónimos o cuasi } \\
\text { sinónimos }\end{array}$ & $\checkmark$ & No & \\
\hline & $\begin{array}{l}\text { Sustitución } \\
\text { por elementos } \\
\text { correferenciales }\end{array}$ & $\checkmark$ & No & \\
\hline & \multirow{2}{*}{$\begin{array}{l}\text { Sustitución por } \\
\text { hiperónimos y } \\
\text { antónimos }\end{array}$} & $\checkmark$ & No & \\
\hline & & $\checkmark$ & No & \\
\hline & $\begin{array}{l}\text { Sustitución por } \\
\text { proformas léxicas }\end{array}$ & $\checkmark$ & No & \\
\hline \multirow{2}{*}{$\begin{array}{l}\text { El mantenimiento } \\
\text { de los referentes } \\
\text { por procedimientos } \\
\text { gramaticales } \\
\text { *Solo en Rojas } \\
\text { Blanco y Rojas } \\
\text { Porras (2015) }\end{array}$} & Referencia anafórica & $\checkmark$ & No & \multirow{2}{*}{$* \checkmark$} \\
\hline & Elipsis & $\checkmark$ & No & \\
\hline \multirow{4}{*}{$\begin{array}{l}\text { Nivel textual } \\
\text { *Solo en Guerrero } \\
\text { Salazar (s. f. y } \\
\text { 2012) }\end{array}$} & $\begin{array}{l}\text { Carencia de } \\
\text { sistematicidad en } \\
\text { el uso del lenguaje } \\
\text { inclusivo }\end{array}$ & $\checkmark$ & No & $\checkmark$ \\
\hline & $\begin{array}{l}\text { Denominación } \\
\text { redundante }\end{array}$ & $\checkmark$ & No & $\mathrm{NA}^{*}$ \\
\hline & $\begin{array}{l}\text { Composición no } \\
\text { equilibrada }\end{array}$ & $\checkmark$ & No & $\checkmark$ \\
\hline & Salto semántico & $\checkmark$ & No & $\checkmark$ \\
\hline
\end{tabular}




\begin{tabular}{|c|c|c|c|c|}
\hline $\begin{array}{l}\text { Relación texto- } \\
\text { contexto }\end{array}$ & $\begin{array}{l}\text { Asimetría en los } \\
\text { tratamientos de } \\
\text { cortesía }\end{array}$ & $\checkmark$ & No & NA* \\
\hline \multirow{6}{*}{$\begin{array}{l}\text { Asimetría al } \\
\text { nombrar a } \\
\text { las personas: } \\
\text { tratamiento } \\
\text { distinto para } \\
\text { hombres y mujeres } \\
\text { (usualmente más } \\
\text { respetuosos para } \\
\text { varones y más } \\
\text { familiares para } \\
\text { mujeres). } \\
\text { *Solo en Guerrero } \\
\text { Salazar (s.f. y } \\
\text { 2012) }\end{array}$} & $\begin{array}{l}\text { Asimetría al } \\
\text { nombrar personas }\end{array}$ & $\checkmark$ & No & $\checkmark$ \\
\hline & $\begin{array}{l}\text { Denominación } \\
\text { sexuada }\end{array}$ & $\checkmark$ & No & NA* \\
\hline & $\begin{array}{l}\text { Denominación } \\
\text { dependiente }\end{array}$ & $\checkmark$ & No & NA* \\
\hline & $\begin{array}{l}\text { Denominación } \\
\text { infantilizada }\end{array}$ & $\checkmark$ & No & NA* \\
\hline & $\begin{array}{l}\text { Denominación } \\
\text { como categoría } \\
\text { aparte }\end{array}$ & $\checkmark$ & No & NA* \\
\hline & $\begin{array}{l}\text { Denominación } \\
\text { como grupo } \\
\text { homogéneo }\end{array}$ & $\checkmark$ & No & NA* \\
\hline \multirow{3}{*}{$\begin{array}{l}\text { Nivel ideológico } \\
\text { *Solo en Guerrero } \\
\text { Salazar (s.f. y } \\
\text { 2012) }\end{array}$} & $\begin{array}{l}\text { Representar } \\
\text { a mujeres y } \\
\text { hombres a } \\
\text { partir de roles } \\
\text { estereotipados }\end{array}$ & $\checkmark$ & No & NA* \\
\hline & Duales aparentes & $\checkmark$ & No & $\mathrm{NA}^{*}$ \\
\hline & Androcentrismo & $\checkmark$ & No & NA* \\
\hline \multicolumn{5}{|c|}{$\begin{array}{l}\text { NA= No aplica. Fuente: Elaboración propia a partir de Quilis Merín, Albelda Marco y Josep } \\
\text { Cuenca (2012); Guerrero Salazar (2012 y s. f.); Marimón Llorca y Santamaría Pérez (2011); Unidad } \\
\text { de Igualdad [Universidad de Cantabria] (2011); Escrig Gil y Sales Boix (2010); Vicerrectorado de } \\
\text { Ordenación Académica y Formación Permanente y Unidad de Igualdad (s. f.); Unidad de Igualdad de } \\
\text { la UGR [Universidad de Cantabria] (s. f.); Unidad de Igualdad entre mujeres y hombres [Universidad } \\
\text { de Granada] (s. f.); Unidad para la Igualdad entre Mujeres y Hombres [Universidad de Murcia] (s. } \\
\text { f.); Rojas Blanco y Rojas Porras (2015); Dirección para la Igualdad de la UPV/EHU (s. f.); Unidad } \\
\text { de Igualdad [Universidad Politécnica de Madrid] (2010); Unidad para la Igualdad [Universidad de } \\
\text { Sevilla] (s. f.); Oficina de Igualdad [Universidad Nacional de Educación a Distancia] (s. f.); CIEM } \\
\text { (2004); Vicerrectorado de Campus y Desarrollo Social [Universidad de Cantabria] (s. f.); Marcal, } \\
\text { Kelso y Mercè (2011); y datos obtenidos del análisis. }\end{array}$} \\
\hline
\end{tabular}

Al comparar las guías, observamos que hay muchas estrategias que no están incluidas en la guía de la UCR. Primero que todo, a pesar de que el instrumento de la UCR incluye información acerca de lo que se debería decir o no en ciertos temas, tales como la familia o los roles sociales de género, no podríamos entender estas como estrategias en un nivel discursivo, porque no se explican de tal manera que una persona lectora pueda entenderlas como tales, más bien parecen ser citadas como prohibiciones. En lugar de ayudar a lograr los objetivos de la PPL, podrían causar efectos negativos tales como los que mencionamos en §3.1.

De acuerdo con la Tabla 1, hay muchas coincidencias entre las estrategias OIP y las que aparecen en las noticias y los documentos administrativos de nuestro corpus. No obstante, 
también hay estrategias como el uso del pronombre de la segunda persona del singular (usted), que no encontramos mencionado en las guías.

Debemos enfatizar en la frecuencia de "no aplica" (NA) en la Tabla 1, pues hay diversas razones para que esto suceda. Una primera razón sería no contar con los datos; por ejemplo, si no tomamos una estrategia en consideración en nuestro análisis o si no apareció en los resultados al analizar los documentos producidos por la rectoría. Otra razón, y esta es central, es que la categorización o descripción a lo interno de SIP (falta de indicidad hacia la política lingüística de lenguaje inclusivo de género) no fue una meta de nuestra investigación; por tanto, constituye una limitación de este trabajo para entender el nivel discursivo. La tercera razón para marcar como NA es que muchas estrategias son propuestas en términos de "remplazar" o "eliminar" ciertos elementos, lo cual solo podría ser estudiado si el trabajo se enfocara en procesos de escritura, no en el texto como un producto terminado.

A nivel discursivo, a pesar de que tenemos ejemplos del mantenimiento del referente que podrían funcionar para procedimientos léxicos o procedimientos gramaticales en el corpus, debemos enfatizar que hay categorías que no fue posible observar. Por ejemplo, no podríamos analizar la elipsis como una estrategia de lenguaje inclusivo de género; para hacer esto, necesitaríamos un acercamiento cualitativo distinto o trabajar con la escritura como proceso. Para otras estrategias, tales como mantenimiento del referente por procedimientos léxicos, podemos encontrar ejemplos en nuestros datos, pero nuestra propuesta -especialmente por las características de nuestro corpus- no nos permite explorar este fenómeno a profundidad.

Para ampliar nuestro punto, nuestros datos no nos permiten comprender si las estrategias discursivas mencionadas por Guerrero Salazar (s. f. y 2012) se dan en nuestro corpus. Empero, tenemos algunos ejemplos en esta línea; verbigracia, podemos ver un salto semántico en el documento administrativo Acuerdo del Consejo Universitario R-93-2015, donde se cambia abruptamente de lenguaje inclusivo a solo masculino con "nombrados en propiedad" y, al hacer alusión únicamente a hombres, podría cambiar la interpretación:

Con esta modificación se equiparan las posibilidades de formación y beneficios respecto a los otorgados a
funcionarios y funcionarias de la Universidad cuando reciben becas para realizar estudios de posgrados en el
exterior, no se hacen diferenciaciones en cuanto a la cobertura que brinda la Universidad en el otorgamiento de
becas, existen áreas académicas en las que es necesario que el personal tenga el grado de doctorado para poder
ejercer la docencia e incluso ser nombrados en propiedad. Además, la cantidad de personas que obtienen un
posgrado académico en la Universidad de Costa Rica se concentran en áreas especificas con ciertas circunstancias
especiales cuyo trabajo es de interés y posee un valor relevante para la Institución. También, los funcionarios y las
funcionarias que optan por el máximo título de posgrado tienen un periodo de permanencia considerable al servicio
de la Universidad y su intención es continuar haciéndolo en el futuro, por lo que dicha formación será de beneficio
para la unidad de trabajo y para la Institución. (Rectoría, 2015a, p. 4, negrita añadida por la autora)

Cuando agregamos las imágenes a nuestro análisis, también podemos observar asimetría al nombrar a las personas en los páneles citados en \$3.2. También encontramos una composición no balanceada en una de las noticias (Elizondo Lucci, 2015), a pesar de que la palabra 'equipo' es un sustantivo colectivo, la foto y la información podría hacernos creer que se trata de un equipo masculino; solo cuando leemos la noticia completa nos enteramos (gracias a un video) que hay también mujeres en el equipo.

Con respecto a los posibles efectos glotopolíticos, en las 17 guías encontramos ejemplos de la idea de corrección y lenguaje inclusivo de género como una norma (codificación); esta es una característica en común con el instrumento de la UCR y los ejemplos al respecto que 
hemos encontrado en los textos (ej. hipercorrección). En esta línea, la guía de la UCR es más cercana a otras, tales como la de la Universidad de Sevilla, que tiene una fuerte presencia de lo que se puede decir o las maneras en las que algo debe ser dicho.

\section{Discusión}

Después de presentar los principales resultados, es importante confrontarlos con otros datos con la finalidad de llegar a una mejor comprensión de nuestros hallazgos. En primer lugar, en cuanto a la política lingüística de la UCR y su instrumento, estos presentan similitudes con las del Congreso de Intendentes de Uruguay (Furtado, 2013) no solo en las limitaciones de cómo es enunciada la política, sino también en las limitaciones de la guía. Además, podríamos ubicar la guía de la UCR con la mayoría de las guías que, al incluir mayoritariamente estrategias léxico-gramaticales, responde a la segunda ola feminista (Vázquez Hermosilla y Santaemilia Ruiz, 2011).

Tal como hemos visto, al momento de la definición del acuerdo no necesariamente existía una amplia discusión sobre la situación del sexismo en la universidad; sin embargo, existen datos sobre dicha realidad (CIEM, 2001). También existe una carencia de datos para saber si esta información era difundida en la comunidad de manera sistemática o con propósitos específicos. Asimismo, existen más datos acerca de la situación de la mujer en la UCR en los años posteriores (Carcedo, 2007; Carcedo y Amador, 2012); empero, no son mencionados en la PPL cuando alcanza el estatus de política universitaria.

Hay distintos elementos que pueden hacernos considerar consecuencias glotopolíticas de la política lingüística. Dado que observamos una planificación lingüística muy limitada, en la cual los medios de implementación de la política básicamente se restringen a la autoridad y donde la publicación del instrumento (CIEM, 2004) no llena los vacíos de la PPL, la ejecución de la política linguística podría llevarse a cabo acríticamente. En otras palabras, la comunidad podría adoptar estrategias de lenguaje inclusivo de género sin claridad para entender las razones por las cuales existe la política de lenguaje inclusivo de género, en general, y las estrategias de lenguaje inclusivo de género, en particular. La misma situación se da con algunas de las guías universitarias.

Este es un punto crucial que debe ser tomado en consideración. Courtine (2006) entiende lo políticamente correcto como un discurso que tiene una cierta omnipresencia en el discurso público, un poder que usualmente es local y desprovisto de un sujeto específico que lo ejerza, un fenómeno no homogéneo que es definido contextualmente. Para este autor, la corrección política está relacionada con lo que una persona puede decir y cómo debe decirlo en un discurso específico; entiende la ausencia de un sujeto que ejerza poder como una consecuencia de la falta de conceptos de lenguaje, donde subyace una idea de una relación entre lengua y realidad. Como podemos ver, este es un concepto clave para entender el modo en el cual la PPL puede ser interpretada por un segmento de la comunidad de la UCR: con una imposición de lo políticamente correcto.

Fairclough (2003) nos permite discutir esta posición. De acuerdo con este autor, la idea de la corrección política funciona como un discurso para poner resistencia contra ciertas propuestas políticas, especialmente si provienen de la izquierda. Para Fairclough (2003), si hablamos acerca de estrategias y tácticas políticas culturales y lingüísticas en un sentido amplio, podemos llegar a observar la misma estrategia lingüística en la izquierda y la derecha; 
por ejemplo, en la derecha es posible verla en el vocabulario de la economía y el comercio (ej. colaboradores, economía global, recursos humanos): no hay diferencia en la estrategia. No obstante, la diferencia aparece en la arena política, debido a que el discurso sobre lo políticamente correcto es utilizado convenientemente para oponerse solo a ciertos cambios, tales como el lenguaje inclusivo de género. Estas ideas nos permiten entender la necesidad de que este tipo de políticas (incluyendo sus instrumentos) expliciten las causas sociales y políticas por las cuales han sido creadas.

Con esto en mente, podemos retomar el hecho de que existían datos sobre la situación de la mujer en la UCR. Para mejorar la implementación de la PPL, la universidad debería desarrollar nuevas estrategias, tales como difundir información acerca de la realidad institucional de las mujeres. Estos datos deberían también ser tomados en cuenta en los instrumentos de la política. Esto podría ayudar a evitar la resistencia y críticas hacia la política.

De hecho, existen distintas estrategias en la guía de la UCR (CIEM, 2004) que podrían traer consigo consecuencias políticas, tales como separación -como mencionamos entre los resultados-. Estas consecuencias podrían evitarse si se manifestara la relación de las propuestas con los datos existentes (Canal UCR, 2017).

Si nos movemos a los resultados de la ejecución de la política lingüística, es interesante observar que el lenguaje inclusivo de género en español es comúnmente relacionado con la estrategia de reduplicación (Morillo Herrera, s. f.), tal como en 'las profesoras y los profesores'; de hecho, esta estrategia es comúnmente criticada (Lemus, 2001; Bosque, 2012). En nuestro corpus encontramos que, entre las estrategias, la reduplicación aparece en porcentajes bajos tanto en las noticias $(0.05 \%)$ como en los documentos administrativos (10.5 \%). Así las cosas, podríamos pensar que la oposición a esta estrategia en particular se debe al hecho de que es fácil de identificar por quienes utilizan la lengua; no obstante, no encontramos evidencia para apoyar esta idea.

Otro resultado importante es el hecho de que las estrategias léxicas por sí mismas no garantizan el éxito de la implementación del lenguaje inclusivo de género. Al respecto, coincidimos con Calvo (2017), quien señala que los sustantivos colectivos tales como gente podrían no resultar inclusivos cuando nos encontramos ante un salto semántico; la autora ejemplifica este hecho con la canción 'Libertad sin ira'. En esta línea, podríamos decir que una estrategia que por sí misma podría ser entendida como inclusiva (estrategias IP/ OIP según nuestros datos) podría también trabajar como no inclusiva (SIP de acuerdo con nuestras categorías) en un contexto específico. En nuestro corpus, encontramos esta situación específicamente en las noticias, cuando las imágenes guían la interpretación de un texto determinado, como en el uso de equipo. En este sentido, apoyamos la necesidad de sobrepasar los niveles morfosintáctico y léxico de la segunda ola feminista (Vázquez Hermosilla y Santaemilia Ruiz, 2011).

En cuanto a la relación de la guía de la UCR con otros instrumentos, encontramos apoyo a la idea de Bosque (2012) de que la mayoría de las guías no explicitan su autoría. Este es un punto esencial que discutir, dado que hay un vínculo entre esta carencia y la posible comprensión de la PPL como corrección política. Nuestros datos apoyan el hecho de que la participación de profesionales de lengua es casi inexistente en la creación de las guías (Bosque, 2012). Consideramos que la participación de personas del área es necesaria para garantizar estrategias adecuadas para los distintos tipos de documentos y contextos, y para sobrepasar el nivel léxico-gramatical. No obstante, no concordamos con Bosque (2012) cuando afirma que: 
sus autores [de las guías] parecen entender que las decisiones sobre todas estas cuestiones deben tomarse sin la intervención de los profesionales del lenguaje, de forma que el criterio para decidir si existe o no sexismo lingüístico será la conciencia social de las mujeres o, simplemente, de los ciudadanos contrarios a la discriminación. (p. 1).

Nuestro desacuerdo se apoya en el hecho de que, a pesar de que nuestros resultados demuestran la importancia de la participación de este grupo de profesionales para crear este tipo de instrumentos, para garantizar el éxito de la PPL, su ejecución y evaluación, debemos ir más allá de una visión disciplinaria y movernos a una perspectiva interdisciplinaria (Gazzola, 2017). Por tanto, la participación de profesionales de la lengua es esencial para crear el instrumento, pero no excluye la participación de otros campos para lograr las metas y la ejecución de la PPL.

La otra razón para no concordar con Bosque (2012) es que, si entendemos el lenguaje en su relación con la realidad social y política (Voloshinov, 2009), es claro que la contribución de otras disciplinas, tales como sociología y antropología, es básica para el éxito de la PPL. Adicionalmente, si nos movemos a la interfaz política del lenguaje (del Valle, 2014), entendemos que no solo las disciplinas, sino también activistas e individuos pueden participar y contribuir en la discusión; este es un hecho que puede apoyarse en otros ejemplos de PPL (Cooper, 1997). Además, este enunciado resulta básico si tomamos en cuenta la génesis social del lenguaje (Fairclough, 2001; Voloshinov, 2009; Bordieu, 2008).

Si prestamos atención al concepto de lenguaje a lo largo de las guías, observamos que en algunas la relación de lenguaje-cultura podría ser considerada como basada en la hipótesis extrema Whorf-Sapir, pues consideran que el lenguaje crea la realidad y nuestros pensamientos. Al respecto, estas guías están relacionadas con algunas de las críticas (Cooper, 1997) que ha recibido el lenguaje inclusivo de género o con perspectivas desactualizadas de lingüística feminista (Sunderland, 2006). Con esto en mente, podemos argumentar que esas guías que se relacionan más de cerca con la hipótesis también tienen una relación más cercana con la perspectiva feminista de los años setenta (segunda ola feminista), cuando empezó a cobrar importancia el tema del lenguaje inclusivo de género.

Sin embargo, encontramos que la relación entre lenguaje y realidad también es resaltada por trabajos que incluyen el nivel discursivo, tales como Guerrero Salazar (s. f.), que -de acuerdo con Vázquez Hermosilla y Santaemilia Ruiz (2011)- podrían ser ubicadas dentro de la tercer ola feminista. No obstante, la noción de lenguaje en estos trabajos (ej. Guerrero Salazar, s. f.) lo conecta no solo con la realidad, sino también con elementos como la identidad, la sociedad y la política. Además, sería necesario llevar a cabo más análisis para entender si las guías actuales que podrían tener una relación con la hipótesis Whorf-Sapir corresponden con la versión atenuada de la hipótesis que ha ganado popularidad en el presente (Salzmann, Stanlaw y Adachi, 2012).

Al pasar a las definiciones de lenguaje inclusivo de género, observamos que la guía de la Universidad Nacional (Costa Rica) lo define como un posicionamiento individual, pero dicho instrumento parte de la noción de lengua culta (relacionada con los grupos de poder); además, las autoras lo denominan "lenguaje de respeto verbal" (Rojas Blanco y Rojas Porras, 2015, p. 26). En este aspecto, dicha guía coincide con la del Consejo de Intendentes de Uruguay (Furtado, 2013). También observamos que la mayoría de las guías no incluye el concepto de lenguaje inclusivo de género o uso no sexista del lenguaje; en su lugar, definen uso sexista del lenguaje o uso androcéntrico del lenguaje. 
Con respecto a las estrategias para ejecutar esta política lingüística, es importante retomar una de ellas: colectivización / desespecificación, la cual es mencionada en las guías en general como "uso de sustantivos abstractos". De acuerdo con Guerrero Salazar (2012), estos sustantivos

son aquellos que denominan cualidades, sentimientos, emociones, instituciones (rectoría, presidencia, alcaldía, inspección, autoría, adolescencia...). En algunos contextos resulta muy útil la sustitución, si desconocemos su sexo, del nombre con el que se designa a la persona que desempeña un cargo o profesión (gerente, redactor, secretario...) por el que alude al puesto que ocupa, a la titulación que posee o la institución a la que representa (gerencia, redacción, secretaría...) (p. 10).

En nuestro proceso de investigación, primero consideramos que esta estrategia era simplemente el remplazo de un tipo de sustantivo por otro. No obstante, conforme avanzamos en el análisis de nuestros datos empíricos, se hizo claro que no se trataba simplemente de un proceso de remplazo, sino de un proceso semántico con posibles consecuencias políticas y discursivas, tal como mencionamos previamente. Empero, no hemos podido encontrar datos para ampliar estas posibles consecuencias.

Como parte de la discusión, debemos establecer algunas limitaciones de nuestro trabajo. Primero, la principal limitación fue la ausencia de estudios previos de carácter descriptivo sobre el lenguaje inclusivo de género. A pesar de la existencia de guías, este tipo de documentos no es de carácter descriptivo, sino normativo. Por tanto, fue necesario desarrollar nuestro análisis mayoritariamente a partir de categorías emergentes, pero con el reto de considerar la naturaleza prescriptiva de la PPL.

A partir de nuestros resultados, otra posible limitación es no llegar a una explicación adecuada del fenómeno semiótico completo (de la multimodalidad) que participa en la creación del sentido, especialmente en el caso de las noticias. A pesar de que la necesidad de poner atención a las imágenes que complementaban el análisis del modo verbal surgió durante el proceso, tuvimos que limitar el marco y el tipo de análisis debido a la viabilidad. Por la misma razón, no pudimos tomar en cuenta otros modos, como el audio o el video.

Una tercera limitación es no haber profundizado en categorías tales como "sustantivos comunes en cuanto al género". No obstante, esta necesidad emergió al final del análisis; así las cosas, no fue viable de llevar a cabo. La misma situación se dio con la categoría SIP (sin indicidad hacia la política lingüística): no concentrarnos en esta categoría implicó limitaciones para dar cuenta del nivel discursivo.

Finalmente, para estudiar las otras guías de universidades hispanohablantes una limitación fue no poder examinar adecuadamente sus efectos glotopolíticos, pues para hacerlo requeriríamos tomar en cuenta más datos de los contextos, por ejemplo, la existencia o no de una PPL de lenguaje inclusivo de género en cada una de las universidades. La misma limitación podría mencionarse para la UCR, dado que nuestro estudio es una primera aproximación y se enfoca en una instancia específica.

\section{Conclusiones y recomendaciones}

A pesar de que la PPL de uso de lenguaje inclusivo de género fue creada hace más de 10 años, no existe información para entender su avance; tampoco para estudiar los mecanismos que son utilizados para su ejecución ni para desarrollar una evaluación de la política. En otras palabras, a pesar de la presencia de una política lingüística, no podemos hablar de una 
planificación lingüística propiamente en la UCR: la sola publicación del instrumento (CIEM, 2004) no es una garantía de planificación, pues se carece de decisiones sistemáticas para la implementación de la política. En este sentido, la presente investigación es una primera aproximación a la PPL y, aunque también presenta limitaciones que deberán ser compensadas en futuras investigaciones, permite evidenciar retos para que la Universidad mejore su PPL.

Con respecto a la guía de la UCR, podemos concluir que está más relacionada con el feminismo de la segunda ola, dado que incluye mayoritariamente estrategias léxicas y morfosintácticas. Futuros trabajos podrían enfocarse en actualizar el instrumento. También, algunos de los hallazgos de nuestro trabajo podrían ayudar a crear recomendaciones para los géneros estudiados. No obstante, estas recomendaciones no son exhaustivas: existe una necesidad de estudiar los distintos géneros producidos en distintos niveles institucionales utilizando una perspectiva multimodal.

Al movernos a la ejecución de la política, nuestros resultados muestran que existe un alto porcentaje de ejecución en ambos tipos de texto, pero especialmente en los documentos administrativos. Con respecto a las noticias, demostramos que apremia discutir la representación de la mujer en la institución en próximos trabajos.

En cuanto a los efectos glotopolíticos de esta política lingüística y su instrumento, podemos concluir que podrían ser interpretados desde el punto de vista del discurso de la corrección política por una parte de la comunidad; no obstante, si incluimos datos del contexto, la implementación de la política y la manera en que es entendida, podría mejorar. Esto también ayudaría a articular mejor el vínculo entre la política linguiística y otras políticas de género de la institución. Adicionalmente, para profundizar en los efectos glotopolíticos, debería llevarse a cabo más investigación, especialmente tomando en cuenta participantes y niveles distintos de la organización (UCR).

A pesar de que esta no es una comparación exhaustiva, nuestros datos funcionan como un primer paso para entender el lugar de esta PPL particular como parte de una discusión política más amplia, en la cual participan también otras instituciones de educación superior. Nuestra investigación demuestra la necesidad de desarrollar más trabajos descriptivos en cuanto al lenguaje inclusivo de género como fenómeno lingüístico y político.

Para concluir, enfatizamos que la lingüística hispánica tiene el reto de construir el lenguaje inclusivo de género como un fenómeno lingüístico con una génesis social, utilizando una perspectiva empírica; por tanto, entenderlo como un objeto de investigación válido. Hasta el presente, la mayoría de los trabajos que encontramos sobre el tema están escritos desde perspectivas prescriptivas o podrían ser entendidos como opiniones personales o activismo. Consideramos que es posible que esta dificultad se desprenda de la construcción tradicional del objeto de estudio dentro de las disciplinas lingüísticas que han entendido el lenguaje como aislado de la realidad sociopolítica (Bordieu, 2008; Fairclough, 2001), y de las perspectivas prescriptivas que aún encontramos en varios segmentos de la disciplina ${ }^{12}$.

12 Agradecimientos: A Carlos Sánchez Avendaño, por su guía docente para realizar esta investigación. A los profesores Alberto Barahona Novoa y Jorge Murillo Medrano por su acompañamiento en este proceso. A Elvira Narvaja de Arnoux, por hacerme repensar relaciones entre política y lenguaje. 


\section{Bibliografía}

Auroux, S. (2009). Instrumentos lingüísticos y políticas lingüísticas: la construcción del francés. Revista argentina de historiografía lingüística, 1(2), 137-149.

Bosque, I. (2012). Sexismo lingüístico y visibilidad de la mujer. Recuperado de http:// www.rae. es/sites/default/files/ Sexismo_linguistico_y_visibilidad_de_la_mujer_0.pdf

Bourdieu, P. (2008). ¿Qué significa hablar? Economía de los intercambios lingüísticos. Madrid: Akal.

Calvo, Y. (2017). De mujeres, palabras y alfileres: El patriarcado en el lenguaje. Barcelona: Ediciones Bellaterra.

Canal UCR. [Canal15UCR]. (2017, agosto 21). Conferencia: Analizando el sexismo en la academia. [Archivo de video]. Recuperado de https://www.youtube.com/ watch? $\mathrm{v}=\mathrm{uUmVT} 8 \mathrm{bERkI}$

Carcedo, A. (2007). Segundo Balance del estado de la equidad de género en la Universidad de Costa Rica. Recuperado de http://ciem.ucr.ac.cr/IMG/pdf/balance2007.pdf

Carcedo, A. y Amador, D. (2012). Tercer balance del estado de la igualdad de género en la Universidad de Costa Rica. Recuperado de http://ciem.ucr.ac.cr/IMG/pdf/ balance2012.pdf

Centro de Investigación en Estudios de la Mujer (CIEM). (2001). Balance sobre el estado de la equidad de género en la Universidad de Costa Rica. Recuperado de http://ciem.ucr. ac.cr/IMG/pdf/balance2001.pdf

Centro de Investigación en Estudios de la Mujer (CIEM). (2004). Guía breve para el uso no sexista del lenguaje: cómo usar lenguaje no discriminatorio en textos varios, presentaciones e ilustraciones. San José, Costa Rica: Universidad de Costa Rica.

Charadeau, P. y Maingueneau, D. (Dir.). (2005). Diccionario de análisis del discurso. Buenos Aires: Amorrortu.

Charaudeau, P. (2004). La problemática de los géneros. De la situación a la construcción textual. Revista Signos, 37(56), 23-39. Recuperado de https://scielo.conicyt.cl/scielo. php?script=sci_arttext\&pid=S0718-09342004005600003

Consejo Universitario. (1974). Estatuto Orgánico de la Universidad de Costa Rica. San José: Universidad de Costa Rica. Recuperado de http://www.cu.ucr.ac.cr/ fileadmin/user_ upload/cu.ucr.ac.cr/Normativa/estatuto/ estatuto_organico.pdf\#page=1

Consejo Universitario. (2003). Acta de la sesión N4814. Universidad de Costa Rica. Recuperado de http://www.cu.ucr.ac.cr/actas/2003/4814.pdf

Consejo Universitario. (27 de marzo de 2006). Política Académica. Aprobación de las políticas institucionales para el 2007. La Gaceta Universitaria. Recuperado de http://www.cu.ucr. ac.cr/uploads/tx_ucruniversitycouncildatabases/officialgazette/2006/g04-2006.pdf

Consejo Universitario. (21 de marzo de 2007). Aprobación de las políticas de la Universidad de Costa Rica para el 2009. La Gaceta Universitaria. Recuperado de http://www.cu.ucr. ac.cr/uploads/tx_ucruniversitycouncildatabases/officialgazette/2007/g05-2007.pdf 
Consejo Universitario. (18 de abril de 2008a). Aprobación de las políticas de la Universidad de Costa Rica para el 2009. La Gaceta Universitaria. Recuperado de http://www.cu.ucr. ac.cr/uploads/tx_ucruniversitycouncildatabases/officialgazette/2008/g07-2008.pdf

Consejo Universitario. (21 de noviembre de 2008b). Políticas institucionales. Aprobación de las políticas de la Universidad de Costa Rica para los años 2010-2014. La Gaceta Universitaria. Recuperado de http://www.cu.ucr.ac.cr/uploads/tx_ ucruniversitycouncildatabases/officialgazette/2008/g40-2008.pdf

Consejo Universitario. (2014). Acta de la sesión №5789. Universidad de Costa Rica. Recuperado de http://www.cu.ucr.ac.cr/uploads/tx_ucruniversitycouncildatabases/ minute/2014/5789.pdf

Consejo Universitario. (5 de junio de 2015). Discusión y aprobación de las Políticas Institucionales para el quinquenio 2016-2020. La Gaceta Universitaria. Recuperado de http://www. cu.ucr.ac.cr/uploads/tx_ucruniversitycouncildatabases/officialgazette/2015/g13-2015.pdf

Cooper, R. (1997). La planificación lingüística y el cambio social. Cambridge: Cambridge University Press.

Courtine, J. J. (2006). A proibição das palavras: a reescritura dos manuais escolares nos Estados Unidos. Metamorfoses do discurso político: as derivas da fala pública (pp. 147-157). São Carlos: Claraluz.

del Valle, J. (2007). Glotopolítica, ideología y discurso: Categorías para el estudio del estatus simbólico del español. En J. del Valle (Ed.). La lengua, ¿patria común? (pp. 13-29). Madrid: Vervuert.

del Valle, J. (2013). Language, Politics, and History: An Introductory Essay. En J. del Valle (Ed.). A Political History of Spanish: The Making of a Language (pp. 3-20). New York: Cambridge University Press.

del Valle, J. (2014). Lo político del lenguaje y los límites de la política lingüística panhispánica. Boletín de Filología, 49(2), 87-112. Recuperado de http://www.scielo.cl/pdf/bfilol/ v49n2/art_05.pdf

Dorner, W. (2010). Feminist, Linguistic, and Rhetorical Perspectives on Language Reform. (Tesis de maestría). University of Central Florida. Orlando, Florida. Recuperado de http://etd.fcla.edu/CF/CFE0003007/ Dorner_William_F_201005_MA.pdf

Dirección para la Igualdad de la UPV/EHU. (s. f.). Guía para el uso no sexista de la lengua castellana y de las imágenes en la UPV/EHU. Recuperado de https://www.ehu.eus/ documents/2007376/0/Gu\%C3\%ADa

Elizondo Lucci, C. (2015). Equipo Nacional de Gimnasia Danesa sorprende a decenas de niños en la UCR. Rectoría. Recuperado de http://www.rectoria.ucr.ac.cr/site/noticias/ noticias-2015/equipo-nacional-de-gimnasia-danesa-sorprende-a-decenas-de-ninosen-la-ucr/

Escrig Gil, G. y Sales Boix, A. (2010). Guía de tratamiento no sexista de la información y la comunicación en la Universidat Jaume I. Unidad de Igualdad de la Universidat Jaume I. Recuperado de http://isonomia.uji.es/wp-content/uploads/2013/06/PDFGyMT-Guia_no_sexista-2010-CAS.pdf 
Fairclough, N. (2001). Language and Power. Essex: Pearson Education Limited.

Fairclough, N. (2003). 'Political correctness': the politics of culture and language. Discurse \& Society, 14(1), 17-28.

Foucault, M. (2002). El orden del discurso. Barcelona: Tusquets.

Furtado, V. (2013). Lenguaje inclusivo como política lingüística de género. Revista Digital de Políticas Lingüísticas, 5(5), 48-70. Recuperado de http://revistas.unc.edu.ar/index.php/ RDPL/article/view/8656/9513

Gazzola, M. [Instituto de Investigaciones Lingüísticas UCR] (29 de agosto de 2017). Evaluation in Language Policy and Planning (LPP) [Archivo de video]. Recuperado de https:// youtu.be/lp2hkKRbLEw

Guerrero Salazar, S. (s. f.). Guía orientativa para el uso igualitario del lenguaje y de la imagen en la Universidad de Málaga. Unidad de Igualdad- Vicerrectorado de Extensión Universitaria de la Universidad de Málaga. Recuperado de http://www.uma.es/media/ tinyimages/file/GUIA_ORIENTATIVA.PDF

Guerrero Salazar, S. (2012). Guía para un uso igualitario y no sexista del lenguaje y de la imagen en la Universidad de Jaén. Jaén: Unidad de Igualdad, Universidad de Jaén. Recuperado de https://www.ujaen.es/servicios/uigualdad/sites/servicio_uigualdad/ files/uploads/Guia_lenguaje_no_sexista.pdf

Guespin, L. y Marcellesi, J. B. (1986). Pour la glottopolitique. Langages, 83, 5-34. Recuperado de http://glottopol.univ-rouen.fr/telecharger/numero_1/ arcglottopolitique.pdf

Guzmán Stein, L. (1997). Gender Studies at the Universidad de Costa Rica. En I. A. Leitinger (Ed.). The Costa Rican Women's Movement: a Reader (pp. 287-292). Pittsburgh: University of Pittsburgh Press.

Guzmán Stein, L. (Comp.). (2001). Antología sobre sexismo y procesos de exclusión en la academia. Manuscrito inédito.

Guzmán Stein, L. (Comp.). (2002). Antología \#1: el diseño curricular alternativo y sexismo en la educación superior. (Manuscrito inédito).

Guzmán Stein, L. y Letendre Morales, A. (2003). Género y Educación en Costa Rica. Recuperado de http://unesdoc.unesco.org/images/0014/001467/146775s.pdf

Hanks, W. (2000). Indexicality. Journal of Linguistic Anthropology, 9(1-2), 124-126.

Huertas Jiménez, L. (27 de noviembre de 2003). En UCR Acuerdan eliminar lenguaje sexista. Semanario Universidad. Recuperado de http://semanariouniversidad.ucr.cr/ universitarias/en-ucr-acuerdan-eliminar-lenguaje-sexista/

Infoterm. (2005). Guidelines for terminology policies. Formulating and implementing terminology policy in language communities. Recuperado de http://unesdoc.unesco. org/images/0014/001407/140765e.pdf

Lemus, J. (2001). Sexismo en el lenguaje: mitos y realidades. Memorias del Encuentro de la Red Centroamericana de Antropología. Asociación Salvadoreña de Antropología, San Salvador. Recuperado de https://www.researchgate.net/publication/228797005_ Sexismo_en_el_lenguaje_mitos_y_realidades 
Marimón Llorca, C. y Santamaría Pérez, I. (2011). Guía para un discurso igualitario. Universidad de Alicante. Recuperado de http://rua.ua.es/dspace/handle/10045/18083

Marcal, H., Kelso, F. y Mercè, N. (2011). Guía para el uso no sexista del lenguaje en la Universitat Autònoma de Barcelona. Barcelona: Servicio de Lenguas y Observatorio para la Igualdad. Recuperado de https:/www.uab.cat/Document/964/953/Guia_uso_ no_sexista_lenguaje2,0.pdf

Martínez Rocha, E. (2009). Más allá de las(os) estudiantas y estudiantes: lenguaje inclusivo en la UCR. Boletina Informativa, $\mathrm{N}^{\circ} 6$.

Mora Vargas, P. (13 de mayo de 2015). Universidad repasa su legado durante 75 años en I Foro Institucional 2015. Rectoría. Universidad de Costa Rica. Recuperado de http://www. rectoria.ucr.ac.cr/site/noticias/noticias-2015/universidad-repasa-su-legado-durante-75anos-en-i-foro-institucional-2015/

Mora Vargas, P. (14 de octubre de 2015). II Foro Institucional 2015 hace diagnóstico de situación actual del país. Rectoría. Universidad de Costa Rica. Recuperado de http:// www.rectoria.ucr.ac.cr/site/noticias/noticias-2015/ii-foro-institucional-2015-hacediagnostico-de-situacion-actual-del-pais/

Morillo Herrera, L. (s. f.) Repercusión mediática del informe de Ignacio Bosque: «Sexismo lingüístico y visibilidad de la mujer».(Tesis de grado en Filología hispánica). Recuperado de http://www.lenguayprensa.uma.es/documentos/repmediaticadelinforme.pdf

Narvaja de Arnoux, E. y del Valle, J. (2010). Las representaciones ideológicas del lenguaje: discurso glotopolítico y panhispanismo. Spanish in Context, 7(1), 1-24. doi: https://doi. org/10.1075/sic.7.1.01nar

Ocampo Álvarez, Á. (2010). Conocimiento y política en las universidades latinoamericanas. San José, Costa Rica: Editorial UCR.

Oficina de Igualdad [Universidad Nacional de Educación a Distancia]. (s. f.). Guía de lenguaje no sexista. UNED. Recuperado de https://www.udc.es/export/sites/udc/ oficinaigualdade/_galeria_down/documentos/GUIA_LENGUAJE.PDF

O’Halloran, K. L. (2012). Análisis del discurso multimodal. Revista Latinoamericana de Estudios del Discurso, 12(1), 76-98.

O’neal Coto, K. (2012). Expertos de la lengua señalan desaciertos del lenguaje inclusivo. Universidad de Costa Rica. Recuperado de https://www.ucr.ac.cr/noticias/2012/10/03/ expertos-de-la-lengua-senalan-desaciertos-del-lenguaje-inclusivo.html

Pauwels, A. (1998) Feminist Language Planning: has it been worthwhile? Linguistik online, 1, 1-98. doi: https://doi.org/10.13092/lo.2.1043

Quilis Merín, M., Albelda Marco, M. y Josep Cuenca, M. (2012). Guía de uso para un lenguaje igualitario (castellano). Tecnolingüística: Universitat de Valencia. Recuperado de http://www.uv.es/igualtat/GUIA/GUIA_CAS.pdf

Rectoría. (2015a). Acuerdo del Consejo Universitario R-162-2015. Rectoría. Recuperado de http://www.rectoria.ucr.ac.cr/site/wp-content/uploads/2015/11/ACU-R-162-2015.pdf 
Rectoría. (2015b). Acuerdo del Consejo Universitario R-93-2015. Rectoría. Recuperado de http://www.rectoria.ucr.ac.cr/site/wp-content/uploads/2015/07/ACU-R-93-2015.pdf

Rivera Alfaro, S. (2018). La planificación lingüistica de la Universidad de Costa Rica: de la política lingüística de uso de lenguaje inclusivo de género a su ejecución textual. (Tesis de Maestría en Filología española). Universidad de Costa Rica, Costa Rica.

Rojas Blanco, L. y Rojas Porras, M. (2015). Guía de uso del lenguaje inclusivo de género en el marco del habla culta costarricense. Heredia: Instituto de Estudios de la Mujer. Recuperado de http://repositorio.ciem.ucr.ac.cr/handle/123456789/192

Salzmann, Z., Stanlaw, J. M. y Adachi, N. (2012). 12 Language, Culture, and Thought. En Languague, Culture, and Society: An Introduction to Linguistic Anthropology (pp. 225-256). Estados Unidos: Westview Press.

Sunderland, J. (2006). Language and Gender: an advance resource book. New York: Routledge.

Unidad de Igualdad [Universidad Politécnica de Madrid]. (2010). Manual de lenguaje no sexista. Universidad Politécnica de Madrid. Recuperado de http://www.upm.es/UPM/ PoliticasIgualdad/LenguajeNoSexista

Unidad de Igualdad [Universidad de Cantabria]. (2011). Guía UC: Comunicación en igualdad. Vicerrectorado de Difusión del Conocimiento y Participación Social. Universidad de Cantabria. Recuperado de https://www.upm.es/sfs/Rectorado/Gerencia/Igualdad/ Lenguaje/Guia_\%20uc_comunicacion_en_igualdad.pdf

Unidad de Igualdad de la UGR [Universidad de Granada]. (s. f.). Guía de lenguaje no sexista. Universidad de Granada. Recuperado de http://secretariageneral.ugr.es/bougr/pages/ desarrollo/2009/guia211209/!

Unidad de Igualdad entre mujeres y hombres [Universidad de Granada]. (s. f.). Guía de lenguaje no sexista. Granada: Universidad de Granada. Recuperado de http://unidadigualdad. ugr.es/pages/documentos/guiadellenguajenosexista/!

Unidad para la Igualdad [Universidad de Sevilla]. (s. f.). Herramientas para el uso del Lenguaje no sexista. Recuperado de http://igualdad.us.es/pdf/Lenguaje-No-Sexista.pdf

Unidad para la Igualdad entre Mujeres y Hombres [Universidad de Murcia]. (s. f.). Guía de uso no sexista del vocabulario español. Universidad de Murcia. Recuperado de https:// www.um.es/documents/2187255/2190475/guia-leng-no-sexista.pdf/d7257202-d5884f11-8d1b-3ac13fd1f5be

Vázquez Hermosilla, S. M. y Santaemilia Ruiz, J. (2011). Las guías de uso no sexista del lenguaje: la situación de la lucha por la igualdad entre mujeres y hombres en la Universitat de València. Revista Philologica Romanica, 11, 171-186. Recuperado de https://dialnet.unirioja.es/servlet/articulo?codigo $=4243806$

Vicerrectorado de Campus y Desarrollo Social [Universidad de Cantabria]. (s. f.). Guía del uso de Lenguaje no sexista. Recuperado de https:/www.um.es/estructura/unidades/uigualdad/recursos/guia-lenguaje-no-sexista-cantabria.pdf 
Vicerrectorado de Ordenación Académica y Formación Permanente y Unidad de Igualdad. (s. f.). Guía del lenguaje no sexista de la Universidad de Castilla-La Mancha. Recuperado de https://igualdad.uniovi.es/c/document_library/get_file?uuid=5013814e-cfd3-47279927-55317ff6beb9\&groupId=336079

Voloshinov, V. N. (2009). El marxismo y la filosofía del lenguaje. Buenos Aires: Ediciones Godot. 